\title{
Making sense of nonsense in British Sign Language (BSL): The contribution of different phonological parameters to sign recognition
}

\author{
Eleni Orfanidou and Robert Adam \\ City University, London, England \\ JAMES M. MCQUEEN \\ Max Planck Institute for Psycholinguistics, Nijmegen, The Netherlands \\ AND \\ GARY MORGAN \\ City University, London, England
}

\begin{abstract}
Do all components of a sign contribute equally to its recognition? In the present study, misperceptions in the sign-spotting task (based on the word-spotting task; Cutler \& Norris, 1988) were analyzed to address this question. Three groups of deaf signers of British Sign Language (BSL) with different ages of acquisition (AoA) saw BSL signs combined with nonsense signs, along with combinations of two nonsense signs. They were asked to spot real signs and report what they had spotted. We will present an analysis of false alarms to the nonsense-sign combinations - that is, misperceptions of nonsense signs as real signs (cf. van Ooijen, 1996). Participants modified the movement and handshape parameters more than the location parameter. Within this pattern, however, there were differences as a function of AoA. These results show that the theoretical distinctions between formbased parameters in sign-language models have consequences for online processing. Vowels and consonants have different roles in speech recognition; similarly, it appears that movement, handshape, and location parameters contribute differentially to sign recognition.
\end{abstract}

In the present study, we examine how different phonological parameters of signs are used during sign recognition. There is consensus in accounts of sign-language phonology that handshape, movement, and location constitute the major manual phonological parameters of signs (see, e.g., Stokoe, Casterline, \& Croneberg, 1965). In current models (e.g., Sandler, 1989), location is considered to be the homologue of consonants in spoken words, and movement the homologue of vowels. Handshape has a dual status: If there is a handshape change within the sign, then handshape assumes a vocalic status; if the handshape does not change, then it serves a more consonantal function (Brentari, 1990; Corina, 1990; Perlmutter, 1992). Therefore, in the present study, we ask whether handshape, movement, and location parameters in British Sign Language (BSL) play different roles in the online recognition of signs. In particular, are there sign-language parallels to consonant-vowel differences seen in speech recognition?

Data from the word-reconstruction task (Cutler, Sebastián-Gallés, Soler-Vilageliu, \& van Ooijen, 2000; van Ooijen, 1996) suggest that different phonemes make different contributions to spoken-word recognition. In this task, participants were asked to turn nonwords into real words by changing single sounds. Vocalic reconstructions (e.g., eltimate to ultimate) were faster and more frequent than consonantal ones (e.g., eltimate to estimate). These results (and others: Moates, Bond, \& Stockmal, 2002; Moates \& Russell, 1999) suggest that listeners treat vowels as being more susceptible to change than consonants, and hence as being less reliable in constraining lexical access. Other differences between consonant and vowel processing include the following: Consonants are perceived more categorically than vowels (Repp, 1984); consonants can be detected faster than vowels (van Ooijen, Cutler, \& Norris, 1992); and consonant and vowel production can be selectively impaired in aphasia (Caramazza, Chialant, Capasso, \& Miceli, 2000). In artificial-language experiments (Bonatti, Peña, Nespor, \& Mehler, 2005, 2007), consonants appear to be used more than vowels in the identification of the nonsense words, whereas vowels are used more in the extraction of language rules.

A consonant-vowel difference has also been observed in an analysis of listener misperceptions in the word-spotting task. In this task, participants try to spot real words embedded in nonsense contexts (e.g., lecture in moinlecture); they are asked to press a button and then report what they

E.Orfanidou, eleni.orfanidou.1@city.ac.uk 
think they heard. Van Ooijen (1996) found that when participants produced false alarms (i.e., by reporting a real word that differed from a nonsense stimulus), vowel changes vastly outnumbered consonantal changes. In line with the data from the word-reconstruction and artificiallanguage experiments, these results suggest that vowel identity is more mutable than consonant identity during spoken-word recognition.

Are there similar differences in sign recognition? Natural signed languages have complex linguistic structures that are perceived, processed, and produced in the visualmanual modality. They have hierarchical organization at the level of sign form (Sandler \& Lillo-Martin, 2006), with handshape, movement, and location being identified as the major parameters. Using an analysis of misperceptions in sign recognition similar to that in van Ooijen (1996), we ask in the present article whether the phonological parameters of signs vary in their perceptual mutability. That is, just as consonants appear to carry more weight than do vowels in speech recognition, do some parameters carry more weight than do others in sign recognition?

We developed a BSL variant of the word-spotting task (Cutler \& Norris, 1988; McQueen, 1998). Deaf BSL signers looked at sequences of two signs, which sometimes consisted of a real BSL sign paired with a nonsense sign, and sometimes consisted of two nonsense signs. The signers were asked to press a button as soon as they saw a real sign and to report back (by signing to a video camera) what they saw. As in the spoken-language version of the task, signers sometimes produced false alarms (i.e., reported a real sign in response to nonsense input). We will report an analysis of those false alarms, following van Ooijen (1996), and we will refer to the false alarms as "misperception errors."

We will address the contribution that the different phonological parameters of BSL make to sign recognition. Previous research on BSL and American Sign Language (ASL) (e.g., Dye \& Shih, 2006; Emmorey \& Corina, 1990; Hildebrandt \& Corina, 2002), including developmental (e.g., Karnopp, 2002; Meier, 2000; Morgan, 2006; Siedlecki \& Bonvillian, 1993) as well as neuropsychological (Corina, 2000) studies, has found differences between parameters in sign comprehension and production. But to our knowledge, there are no previous data on online misperception errors in signed languages.

\section{Sign Phonology}

The main parameters identified by Stokoe et al. (1965) were handshape, movement, and location. Although there is no set of defined rules on sign well-formedness in BSL, the results of studies in ASL sign phonology (Brentari, 1998; Sandler, 1989) are in agreement that these three parameters must always be present in a sign. Others have suggested the addition of two other components: orientation (the direction in which the palm and fingers face) and facial expression (Liddell \& Johnson, 1989). Recently, however, the status of orientation as a major category has been questioned. Sandler and Lillo-Martin (2006) included orientation in the handshape category, whereas Brentari (1998) and Crasborn and van der Kooij (1997; see also Crasborn, 2001) treated it as a relative notion, interpreted as a combination of handpart and location. Hohenberger, Happ, and Leuninger (2002) noted that hand orientation errors are very rare in slips of the hand in German Sign Language. For these reasons, we do not include orientation as a separate category, and instead report orientation errors in the handshape category. Facial expression was also ignored. The stimuli all contained the same neutral facial expression (Brentari, 2006) because it would have been difficult for the signer who made the stimuli to produce facial expressions and mouthings for nonsense signs. Misperceptions never involved nonneutral facial expressions.

Handshape. According to Jakobson (1941/1968), some handshapes are less marked than others (i.e., they are frequent in different languages, easy to produce, are the earliest to be acquired, and are less affected in aphasia). Sutton-Spence and Woll (1999) wrote that four handshapes in BSL are unmarked: " 5 " (spread hand), " $A$ " (fist), "G" (index finger point), and "B" (flat hand). This small group of handshapes is used in $50 \%$ of the BSL lexicon. Within a single sign, when there are two handshapes, they are usually open and closed versions of the same handshape, or one or both handshapes are unmarked (Battison, 1978; Brentari, 2006). Handshape can either be "vocalic" (when it changes within a sign) or "consonantal" (when it does not) (Brentari, 1990; Corina, 1990; Perlmutter, 1992; see also Corina \& Hildebrandt, 2002, for a relevant experiment).

Movement. There are two main types of movements: path movements, which move from one location to another and are articulated by the elbow or shoulder, and internal or local movements, which are articulated by the wrist or the hand and include either a change of handshape or a change of orientation. It is not clear how to classify handinternal movements. Within the hand tier model (Sandler, 1989), they are represented as handshape parameters, but in the prosodic model (Brentari, 1998), they are treated as movement parameters. Path movements also have a shape (straight, circle, or arc). It is assumed that straight is the default path shape (Sandler \& Lillo-Martin, 2006). Path movements, because of their role in the phonology, are considered to be the "vowels" (Liddell \& Johnson, 1989) or syllable nuclei (Brentari, 1990; Perlmutter, 1992) of signs. For example, all well-formed signs must have a movement, just as words have a syllabic nucleus (i.e., a vowel or a syllabic consonant). Furthermore, movement is considered to be vocalic because, like a vowel, a sign's movement is dynamic, has a temporal quality, and changes during the articulation of the sign.

Although most signs are monosyllabic (i.e., have only one movement), there are also disyllabic signs. For disyllabic signs in ASL, a number of constraints on the combinations of movement features have been proposed (Brentari, 2006; Uyechi, 1996). For example, it is acceptable to repeat the same movement or combine a circle and straight movement, but other combinations are not permissible (e.g., straight and arc, straight and circle). In addition, combinations of a path movement with an internal movement (handshape change or orientation change) as 
well as combinations of two internal movements (handshape change plus orientation change) are not acceptable in monomorphemic signs or compounds of ASL (Brentari, 2006; Perlmutter, 1992). Although these constraints have been proposed for ASL, they seem to hold for BSL as well.

Location. Location (otherwise known as place of articulation) specifies distinctive regions of the body - head, trunk, arm, neutral space, and the nondominant handas well as three-dimensional planes (the horizontal, the vertical, and the midsagittal planes). In monomorphemic signs, there is typically one distinctive location (Sandler, 1989). If there are two locations, these are contained within a single major body area, such as the head or the trunk (Battison, 1978). This observation is referred to as Battison's place constraint: "There can be only one major body area specified in a sign" (Sandler \& Lillo-Martin, 2006, p. 138). Location is considered to be consonantal (Brentari, 1998).

\section{Phonological Parameters in Lexical Access}

Phonological parameters are used both in phonological coding in the working memory of deaf signers and in sign recognition processes (see, e.g., Bellugi, Klima, \& Siple, 1975; Dye \& Shih, 2006; Wilson \& Emmorey, 1997). It is likely, however, that they are not used to the same degree during lexical access. For example, Emmorey and Corina (1990) investigated the temporal uptake of phonological information by native signers of ASL. Location was identified first, followed by handshape and, finally, movement. It was the isolation of the movement that led to sign recognition. Corina and Emmorey (1993) investigated form-based priming in ASL using a lexical decision task. Inhibitory effects were found when targets shared an articulatory location with the primes. When primes and targets shared movement, facilitatory effects were found. When they shared a common handshape, neither facilitation nor inhibition was found. Conversely, Corina and Hildebrandt (2002) investigated movement and location priming activation at $500-$ and $100-\mathrm{msec}$ interstimulus intervals (ISIs). They found no evidence of phonological priming for either movement or location at a 500-msec ISI, although an inhibitory nonsignificant trend was observed for both location and movement at a 100-msec ISI. A recent study in Spanish Sign Language (Carreiras, Gutiérrez-Sigut, Baquero, \& Corina, 2008) found differences between the parameters of location and handshape: For low-familiarity signs, a location with high neighborhood density slowed down lexical decision responses, whereas a handshape with high neighborhood density facilitated responses. In addition, inhibitory priming was found for prime-target pairs that shared location (as in ASL; Corina \& Emmorey, 1993), whereas facilitation was observed for nonsense signs (but not for real signs) sharing the same handshape. Finally, differences between handshape and location have been observed in sign perception (Emmorey, McCullough, $\&$ Brentari, 2003): Handshape is perceived categorically, but location is not.

In summary, the location parameter is identified first during lexical access and produces inhibitory priming effects. Since location thus seems to be importantespecially in guiding the early stages of lexical accesswe predict that it will be less often misperceived than will the handshape and movement parameters. A different type of prediction derives from the suggestion that movements are akin to vowels (see, e.g., Brentari, 1998). Since vowels are more mutable than consonants in spoken-word recognition (van Ooijen, 1996), then it stands to reason that if sign movements are indeed vocalic, the movement parameter should be misperceived more often than the "consonantal" location parameter (and, to a lesser extent, the handshape parameter).

\section{Age of Acquisition}

In spoken-language acquisition, most children are exposed to fully complex models of their first language from birth. In the deaf population, contexts of first-language learning are radically different. The majority of deaf adults are not native users of a signed language because fewer than 1 in 10 deaf children are born to deaf parents who use sign at home. Many deaf children have their first full exposure to their first language in late childhood. We thus compared the misperceptions of native signers with those of signers who first acquired BSL as either children or adolescents.

Research on ASL and other signed languages has shown that age of acquisition (AoA) predicts performance on a variety of tasks (Carreiras et al., 2008; Mayberry, Lock, \& Kazmi, 2002; Newport, 1990). In particular, Mayberry et al. (2002) showed that during sentence shadowing, late learners of ASL produce a disproportionate number of phonological substitutions (i.e., signs that are phonologically similar to the target signs but that differ in meaning) in comparison with native signers. This result suggests that delayed learners of ASL, as compared with native signers, must focus more attention on the phonological form of signs during processing and thus have fewer resources to apply to deeper levels of sign comprehension (Mayberry, 1994; Mayberry \& Fischer, 1989).

There may also be differences in the role of sign parameters as a function of AoA. Corina and Hildebrandt (2002), in a sign similarity judgment task, found that signers rated signs that shared location and movement as being more similar than signs sharing any other combination of phonological features. There were also differences between late learners and native signers in which phonological components were perceived as most salient. Although all signers reported that movement properties were most salient, nonnative signers' responses also indicated that handshape was the most important factor. Dye and Shih (2006) reported that native BSL signers showed facilitatory phonological priming for signs that shared location and movement, but that for late signers, priming was based on shared movement alone. These results suggest that it is the combination of movement and location parameters that serve as initial input for lexical access in native signers, but that movement may be more critical for nonnative signers (see also Corina \& Knapp, 2006).

These considerations do not generate clear predictions about AoA effects in the present article. On the one hand, 
if nonnative signers are more focused on the phonological form of signs, then they could be very good at identifying nonsense signs as nonsense, and thus make fewer errors than natives. On the other hand, if nonnative signers are generally less efficient in sign processing, then they could have more misperceptions than natives. In addition, there may be differences between native and nonnative signers in the specific phonological parameter affected (Corina \& Hildebrandt, 2002; Corina \& Knapp, 2006; Dye \& Shih, 2006).

\section{Sign Phonotactics}

We also looked at deaf signers' sensitivities to the phonotactic structure of the signs. Phonotactic constraints on possible syllabic structures are specific to individual spoken languages and are an integral part of the knowledge that speakers acquire. Sensitivity to phonotactic constraints in speech comprehension has been documented in several spoken languages using the word-spotting task (e.g., in the French language, Dumay, Frauenfelder, \& Content, 2002; and in the Dutch language, McQueen, 1998). Although there is no clearly defined set of phonotactic rules of well-formedness for BSL, there is one main principle. Within a sign, a change from one distinctive handshape, location, or movement to another is not permitted (but allophonic changes are permitted). Even in special cases (e.g., compounds), combinations of unmarked handshapes and permissible combinations of movement tend to occur (Brentari, 2006). This "compound principle" was violated in order to create some of the nonsense signs used in the present article. It is possible that phonotactic constraints on possible sign structures constitute part of the implicit knowledge that signers have, especially if they are native learners. If so, then their misperceptions ought to rectify irregularities in the phonotactics of BSL, including violations of the compound principle. This would be analogous to the tendency of listeners to hear phonotactically illegal sounds as sounds that are legal in that context (e.g., in French, [tl] heard as [kl]; Hallé, Segui, Frauenfelder, \& Meunier, 1998). There should therefore be more misperceptions of phonotactically illegal nonsense signs than of legal ones, but this may be affected by AoA.

\section{METHOD}

\section{Participants}

Fifty-two deaf BSL signers between 18 and 60 years of age took part. Twenty-nine were native deaf BSL signers (exposed to sign before 5 years of age), 10 were childhood BSL signers (exposed to sign between 6 and 12 years of age), and 13 were adolescent BSL signers (exposed to sign after 12 years of age). All had normal or corrected visual acuity. Participants predominantly included professional deaf people (teachers, managers, academics, etc.) who demonstrated no cognitive delays due to late exposure to BSL. The remaining participants completed the Raven's matrices test of cognitive abilities (Raven, 1938), and all scored within the normal range. Each participant completed a questionnaire about his/her sign-language exposure (e.g., parents' level of signing, extent of mixed language/sign use in the home), socioeconomic background, and academic qualifications, including level of English fluency. All participants were deaf and presented as people who used BSL as their first or dominant everyday language; all were congenitally and profoundly deaf.

\section{Stimuli}

The stimulus set consisted of 64 items that were combinations of two nonsense BSL signs and another 32 that were combinations of a nonsense sign followed by a real BSL sign. In the present article, we report misperception data from the 64 nonsense combinations only (for the data on detection of the real BSL signs, see Orfanidou, Adam, Morgan, \& McQueen, 2008). Initially, a native deaf signer produced 200 nonsense signs. Four other native deaf signers evaluated whether these signs were indeed nonexistent signs in BSL and its regional dialects. Forty-two items were excluded, and 128 of the remaining items were used to construct the 64 nonsense-sign combinations.

In order to make some of the stimuli, we used illegal parameter combinations (i.e., phonotactically illegal combinations of handshape, movement, location, and orientation). For example, it is extremely rare in BSL to see a sign with a movement between two different phonological locations (e.g., from head to nondominant hand). Note that it would have been inappropriate to use only phonologically legal nonsense signs in the set of nonsense combinations. The nonsense signs that served as the contexts for the BSL signs (i.e., those in first position in sign-bearing sequences) varied in their phonological legality (in fact, this was the critical manipulation in these stimuli; for details, see Orfanidou et al., 2008). The nonsense signs in first position in the nonsense combinations thus also had to vary in legality (specifically, half used legal and the other half used illegal combinations of parameters). All of the nonsense signs in second position in the nonsense combinations were legal (otherwise participants could have spotted targets simply by detecting that they were not ill formed). In total, therefore, there were 96 legal signs in the nonsense combinations ( 32 in first position and 64 in second position) and 32 illegal signs (all in first position). These nonsense signs included a variety of handshapes (marked and unmarked), locations (major body areas - head, trunk, neutral space, nondominant hand-and specific locations within these major areas), and movements (straight, arc, circle). Ten of the nonsense signs in first position were disyllabic (i.e., had two movements).

The inclusion of phonologically illegal nonsense signs allowed us to examine effects of phonotactic constraints in BSL. We coded the stimuli in terms of their phonological complexity (i.e., which and how many phonological parameters they included: handshape, path movement, internal movement, location, orientation, and one or two hands). We considered that a sign made up of one straight path movement, one location, and one unmarked handshape was of zero complexity (Sandler \& Lillo-Martin, 2006). We included nonsense signs ranging mainly from $0^{\circ}$ to $6^{\circ}$ of complexity (there were five with complexity greater than $6^{\circ}$ ). For example, if a nonsense sign had a marked handshape or two separate locations, it was given 1 point of complexity. The average complexity of the nonsense signs in the nonsense combinations was 1.95 . There was no difference between the complexities of the first and second nonsense signs of each combination $[t(63)=-1.3, p=.198]$.

The materials were signed to digital video by a deaf native BSL singer who practiced each sign in isolation to achieve fluency across all the signs and then produced them in the prescribed two-sign sequences. Since it is impossible to mouth an appropriate English word during a nonsense sign, the signer was instructed not to mouth spoken words (i.e., for either the nonsense or the BSL signs). The filming of the materials took place in a professional studio. Clips were edited into separate files using iMovie software.

\section{Procedure}

Each session started with a practice block, followed by two blocks of the experiment proper. Each main block contained, in random order, 32 nonsense combinations and 16 combinations of a nonsense sign followed by a real BSL sign. The stimuli were presented on 
a 19-in. computer screen using DMDX (Forster \& Forster, 2003). Each trial lasted $7 \mathrm{sec}$ (stimulus presentation, response window, and pause before the next trial began). Participants were asked to press the right button on a button-box if they saw a real BSL sign and then to sign to the camera in front of them what the sign was. Accuracy feedback was given only during practice. The experiment lasted about $18 \mathrm{~min}$.

\section{RESULTS}

The video taken during the testing of each participant was analyzed by trained coders. One was a hearing, fluent BSL signer, and the other was a native deaf BSL signer. The coding scheme was explained to a third hearing, fluent BSL signer who coded $10 \%$ of the data (taken from 10 participants, chosen randomly). There was a $99 \%$ agreement between his coding and the original coding. Trials in which participants responded to nonsense signs in the sequences of two nonsense signs by pressing the button and signing an existing BSL sign were treated as false alarms and analyzed. Instances in which participants just pressed the button without producing a real BSL sign were excluded.

Misperceptions were coded by the affected phonological parameter and by the type of error. The following parameters were coded: (a) handshape (including orientation errors); (b) path movement (straight, arc, circle); (c) internal movement (aperture, wiggling, twisting, bouncing); and (d) location. Error types were categorized as follows: (1) substitutions - an error that involved the use of a handshape, location, movement, and internal movement that was not present in the stimulus in the place of one that was present (e.g., substitution of the arc movement in the stimulus with a straight movement); (2) omissions - a parameter in the stimulus that was completely absent in the participant's production (e.g., omitting an internal movement such as wiggling); (3) reductions - a parameter was not omitted but appeared reduced (e.g., a circle path made smaller); (4) additions - a parameter was introduced in addition to those already present in the stimulus, which were kept intact (e.g., addition of internal movement such as aperture); and (5) fusions - parts of the second nonsense sign were combined with parts belonging to the first sign (e.g., keeping the handshape and movement of the first nonsense sign but the location of the second nonsense sign).

The total number of trials in which participants produced an error was 678 ( $20 \%$ of the total number of trials). Of those, 430 trials involved a misperception error. The remaining 248 trials were instances in which participants thought they saw a sign (i.e., pressed the response button) but then copied exactly the nonsense sign they saw. In the following analyses, we will focus only on the misperception errors. For each of the 430 trials with misperception errors, we noted all of the changes made to the phonological parameters in the stimulus. Only 190 involved the change of just one phonological parameter (99 misperceptions involved a handshape change, 70 were movement changes, and 21 were location changes). Given that there was more than one parameter change in most trials, the total number of errors that went into the main analyses was $693 . .^{1}$ It should be noted that this pattern of multiple parameter changes is different from that observed in the word-spotting task, in which participants usually made single-segment changes involving either one vowel or one consonant (van Ooijen, 1996, p. 574). We believe that this is due to a difference between the nonsense signs and the spoken nonwords: The nonsense signs were made by changing multiple phonological parameters of real signs, whereas the nonwords tended to differ from real words by only a single segment.

\section{Effects of Phonological Parameter}

We first investigated potential differences among the parameters in the number of misperceptions. Mean number of errors for each type of parameter and each AoA group are shown in Table 1. Due to the lack of consensus in the literature on the treatment of internal movement, we report results from several different analyses. In Analysis 1, internal movement was included as a separate category. In Analysis 2, internal movement was included in one "hand" category with handshape, in line with the hand tier model (Sandler, 1989). In Analysis 3, internal movement was included with path movement in a single "movement" category, in line with the prosodic model (Brentari, 1998).

In Analysis 1, the within-participants factor was phonological parameter, with four levels (handshape, path movement, internal movement, location). To investigate potential AoA effects, we also included group (with 3 levels: native BSL signers, childhood BSL signers, adolescent BSL signers) as a between-participants factor. There was a main effect of parameter $\left[F_{1}(3,147)=29.9, p<.001\right]$. Paired $t$ tests showed that there were more path movement errors than there were errors with any other parameter [path errors vs. handshape, $t_{1}(51)=-2.9, p<.005$; path vs. location errors, $t_{1}(51)=6.0, p<.001$; path vs. internal movement errors, $\left.t_{1}(51)=8.0, p<.001\right]$, more handshape than location errors $\left[t_{1}(51)=2.9, p<.006\right]$, more handshape than internal movement errors $\left[t_{1}(51)=7.6\right.$, $p<.001]$, and more location errors than internal movement errors $\left[t_{1}(51)=4.9, p<.001\right]$.

The main effect of AoA was not significant $\left(F_{1}<1\right)$, but there was an interaction between AoA and parameter $\left[F_{1}(6,147)=2.3, p<.040\right]$. This interaction primarily reflects differences between the adolescent signers and the other two groups. The native and childhood signers produced more path movement errors than errors with any other parameter [path vs. handshape - native, $t_{1}(28)=$ $-3.4, p<.002$, childhood, $t_{1}(9)=-2.0, p=.081$; path vs. location-native, $t_{1}(28)=4.5, p<.001$, childhood, $t(9)=5.3, p<.001$; path vs. internal movement-native, $t_{1}(28)=5.5, p<.001$, childhood, $\left.t(9)=5.5, p<.001\right]$. In contrast, adolescent signers made more handshape than

Table 1

Mean Number of Errors for Each Parameter and Group

\begin{tabular}{lccccc}
\hline & \multicolumn{4}{c}{ Parameter } & Overall \\
\cline { 2 - 5 } \multicolumn{1}{c}{ Group } & Handshape & $\begin{array}{c}\text { Path } \\
\text { Movement }\end{array}$ & $\begin{array}{c}\text { Internal } \\
\text { Movement }\end{array}$ & Location & Means \\
\hline Native & 3.38 & 5.45 & 1.41 & 2.90 & 13.14 \\
Childhood & 3.80 & 5.10 & 1.20 & 3.70 & 13.80 \\
Adolescent & 4.92 & 4.23 & 1.85 & 2.38 & 13.38 \\
Overall & 3.85 & 5.08 & 1.48 & 2.92 & \\
\hline
\end{tabular}


path movement errors, although this difference was not significant [path vs. handshape: $t_{1}(12)=1.5, p=.168$ ] . Location was the least affected major parameter. All groups made fewer location errors than they did handshape and path movement errors. This was particularly the case with adolescent signers [location vs. path, $t_{1}(12)=2.9$, $p<.014$; location vs. handshape, $\left.t_{1}(12)=3.0, p<.011\right]$. For the other two groups, there were fewer location than path movement errors (see previous), but the numerical difference between handshape and location errors was not significant [location vs. handshape: native, $t_{1}(28)=1.4$, $p=.165$; childhood, $\left.t_{1}(9)=0.309, p=.764\right]$.

Analysis 2 was identical to Analysis 1, except that internal movement and handshape were treated as a single "hand" category. Means for the resulting three categories, by AoA, are shown in Figure 1. There was again a main effect of parameter $\left[F_{1}(2,98)=16.6, p<.001\right]$ : more hand and path movement errors than location errors. Separate paired $t$ tests showed no significant difference between path movement and hand errors $\left[t_{1}(51)=0.5, p=.632\right]$, but there were more errors in both of these categories than in the location category [path vs. location, $t_{1}(51)=6.3$, $p<.001$; hand vs. location, $\left.t_{1}(51)=4.8, p<.001\right]$. The main effect of AoA again was not significant $\left(F_{1}<1\right)$, but there was an interaction between AoA and parameter $\left[F_{1}(4,98)=3.2, p<.017\right]$. Separate paired $t$ tests in each group showed the same effects as in Analysis 1. Native and childhood signers changed path movement more than any other parameter [native-path vs. hand, $t_{1}(28)=$ $-1.1, p<.026$, path vs. location, $t_{1}(28)=4.7, p<.001$; childhood — path vs. hand, $t_{1}(9)=-0.21, p<.086$, path vs. location, $\left.t_{1}(9)=5.3, p<.001\right]$. In addition, both of these groups produced fewer location errors than hand errors [native, $t_{1}(28)=3.2, p<.001$; childhood, $t_{1}(9)=$ $2.5, p<.003]$. In contrast, the adolescent signers produced significantly more errors in the hand category than in either of the other categories [path vs. hand, $t_{1}(12)=$
$3.0, p<.001$; hand vs. location, $t_{1}(12)=3.0, p<.001$ ] but again, there were more path movement than location errors $\left[t_{1}(12)=3, p<.011\right]$. The location parameter was therefore the least affected parameter in all three groups.

In Analysis 3, internal movement was collapsed with path movement (see Figure 2). In line with the previous analyses, there was a main effect of parameter $\left[F_{1}(2,98)=\right.$ $24.0, p<.001]$. There were significantly more movement than handshape $\left[t_{1}(51)=-5.4, p<.001\right]$ or location $\left[t_{1}(51)=6.8, p<.001\right]$ errors. Furthermore, there were more handshape than location errors $\left[t_{1}(51)=2.8, p<\right.$ $.007]$. There was no effect of AoA (i.e., no main effect, $\left.F_{1}<1\right)$ and no interaction $\left[F_{1}(4,98)=2.0, p=.099\right]$.

Two patterns emerge across these three analyses and thus do not depend on the treatment of the internal movement parameter. First, for all AoA groups and the three major parameters, the location parameter was involved least often in misperceptions. Second, path movement tended to be the most strongly affected parameter for the native and the childhood signers, but handshape had the most errors for the adolescent signers.

\section{Position Effects}

Next, we compared the number of errors by position (i.e., whether the errors were in response to signs in the first or second position in the nonsense combinations). There was a main effect of position $\left[F_{1}(1,49)=7.405, p<.009\right]$, with more errors occurring in the second position. This effect probably reflects the fact that the real BSL signs were all in second position. The participants' attention was therefore focused on the second position, and their errors thus tended to reflect their attempts to identify nonsense signs in that position as additional real BSL signs.

\section{Effects of Error Type}

An ANOVA was carried out with error type (with five levels: substitution, omission, reduction, addition, and fu-

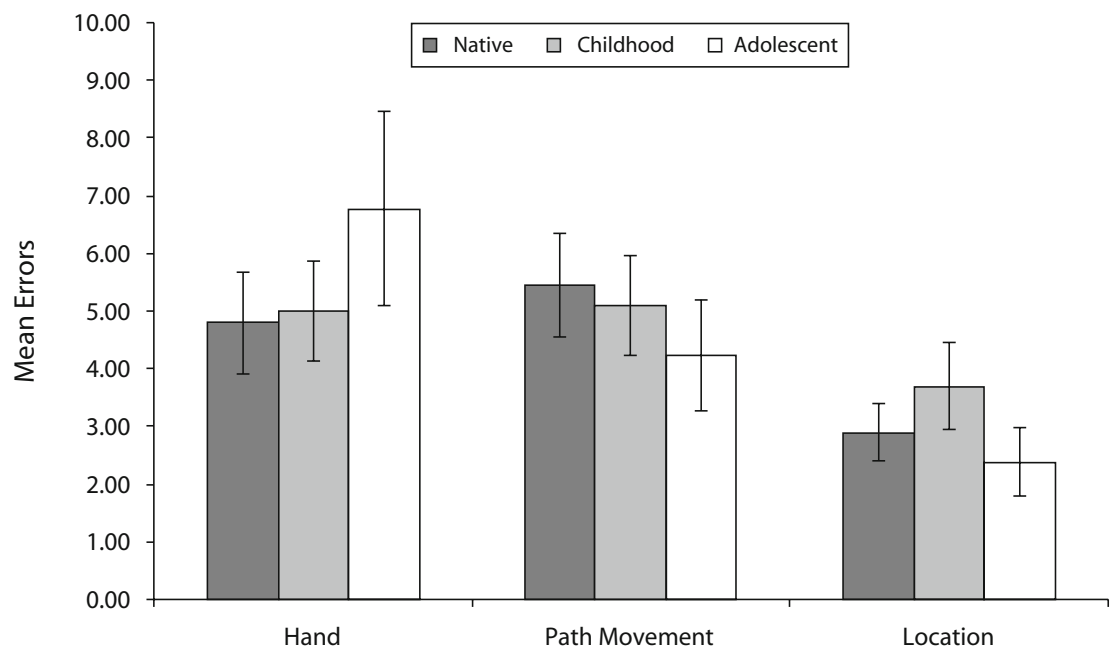

Figure 1. Mean errors for each parameter by group (the "hand" category includes internal movement and handshape errors). Error bars represent 1 standard error. 


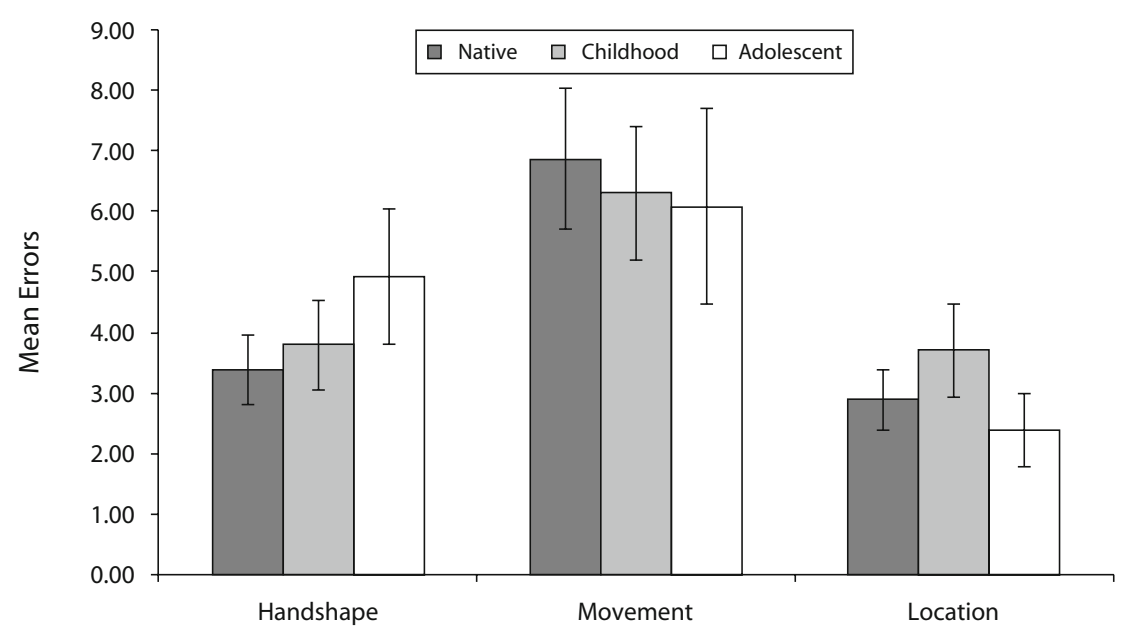

Figure 2. Mean errors for each parameter by group (the "movement" category includes path movement and internal movement). Error bars represent 1 standard error.

sion) as within-participants factor, and AoA as a betweenparticipants factor. There was a main effect of error type $\left[F_{1}(4,196)=34, p<.001\right]$, with more substitution $(n=$ $250)$ and omission $(n=314)$ errors than reduction $(n=$ $54)$, addition $(n=55)$, or fusion $(n=6)$ errors. Pairwise $t$ tests revealed no significant differences between the numbers of substitution and omission errors $\left[t_{1}(51)=\right.$ $-1.6, p=.124]$, and no significant differences between the numbers of addition and reduction errors $\left[t_{1}(51)=\right.$ $-0.8, p=.936]$, but there were significant differences between these two sets [e.g., substitution vs. addition, $\left.t_{1}(51)=7, p<.001\right]$ as well as between fusion errors and all other types (all $p \mathrm{~s}<.001$ ). There were no effects of AoA, either as a main effect $\left(F_{1}<1\right)$ or as an interaction $\left(F_{1}<1\right)$.

The phonological parameter analysis was then compared with the error type analysis. An ANOVA was run with phonological parameter (handshape [including handshape change errors], path movement, internal movement, location) and error type (substitution, omission, addition, reduction) as within-participants factors. Fusion was not included because of the very small number of fusion errors. AoA was a between-participants factor. The results showed a main effect of parameter $\left[F_{1}(3,150)=29.2\right.$, $p<.001]$ and a main effect of error type $\left[F_{1}(3,150)=\right.$ $31.3, p<.001]$. In line with the previous analyses, there was a significant interaction between parameter and AoA $\left[F_{1}(6,150)=2.5, p<.027\right]$. In addition, there was a significant interaction between parameter and error type

Table 2

Sum of Substitution, Omission, Reduction, and Addition Errors for Each Phonological Parameter

\begin{tabular}{lcccc}
\hline & Substitution & Omission & Reduction & Addition \\
\hline Handshape & 151 & 48 & 1 & 0 \\
Path movement & 73 & 131 & 31 & 29 \\
Internal movement & 3 & 50 & 10 & 14 \\
Location & 23 & 105 & 10 & 14 \\
\hline
\end{tabular}

$\left[F_{1}(9,450)=25.5, p<.001\right]$. The data, collapsed over AoA group, are shown in Table 2.

Paired $t$ tests then compared the different parameters for each error type. There were significantly more substitution errors involving handshape than path movement $\left[t_{1}(51)=5.9, p<.001\right]$. In contrast, omission errors for path movement were significantly higher than omission errors for handshape $\left[t_{1}(51)=-6.1, p<.001\right]$. In addition, there were more path movement than location omission errors $\left[t_{1}(51)=-4.8, p<.001\right]$.

Error types were then compared for each phonological parameter. For handshape, there were significantly more substitutions than for any other error type (all $p \mathrm{~s}<.001$ ). Substitutions were simplifications in which a less frequent (or more marked) handshape was substituted by a more frequent or less marked one (see Figure 3). From the total of 128 nonsense signs, 70 had a marked handshape, so there was considerable opportunity for the substitution of marked handshapes by unmarked (or less marked) ones.

Errors of omission involving handshape all consisted of the deletion of one handshape when there were two in the nonsense sign. This is because all signs need at least one handshape. Twenty-six of the 128 nonsense signs had two handshapes. Most of these errors involved the omission of the first handshape (32 cases out of the total 48 handshape omissions). We provide an example in Figure 4. These handshape substitutions and omissions are examples of simplifications (i.e., substitutions of the marked handshape with a simpler, unmarked handshape) but not of legalizations (i.e., turning an illegal sign into a legal one), since it is possible to have BSL signs with two handshapes, usually two unmarked handshapes or a combination of an unmarked and a marked handshape.

The most frequently occurring path movement errors were omissions. There were significantly more omissions than substitutions $\left[t_{1}(52)=-3.7, p<.001\right]$, but substitutions were in turn more frequent than reductions $\left[t_{1}(52)=\right.$ $4.6, p<.001]$ and additions $\left[t_{1}(52)=4, p<.001\right]$. Path 


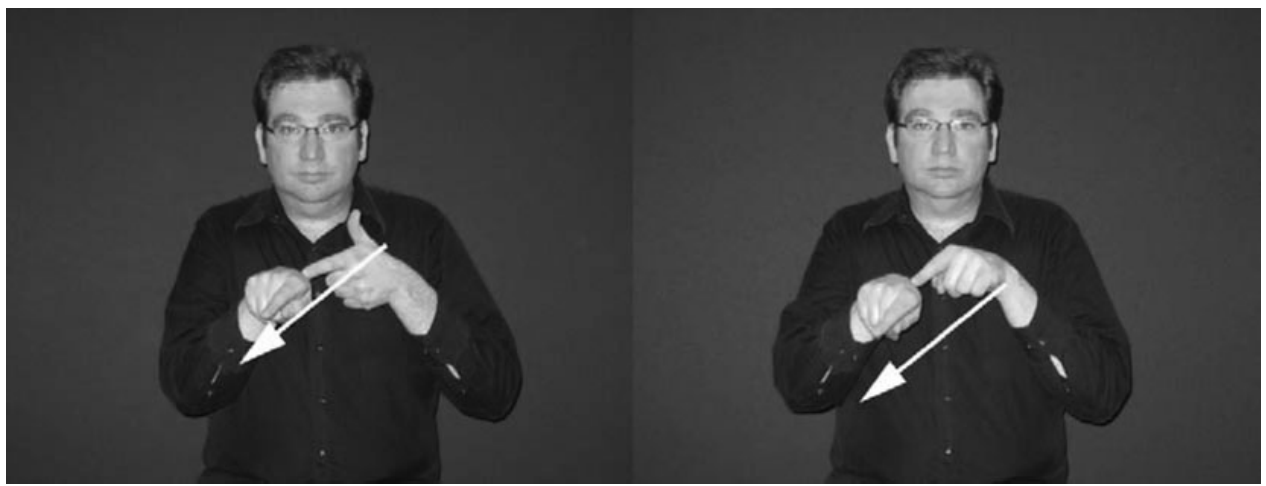

Figure 3. The nonsense sign on the left (with a more marked handshape) was reproduced, as shown on the right, as the BSL sign for FOLLOw (with a less marked handshape). Note that these are reproductions, by the same signer, of a stimulus and a response in the experiment.

movement omissions involved the deletion of a second path in the sign, especially if it was an arc or circle (15 of the 128 nonsense signs had two path movements; out of the 131 path movement omissions, 80 were instances of arc and circle omissions). Path substitutions (in response to the 45 nonsense signs with an arc/circle path) almost entirely involved the substitution of an arc movement with a straight movement (see Figure 4).
Substitutions and omissions of the arc or circle path in the nonsense sign can be considered simplifications of the nonsense signs with permissible combinations of movement (e.g., circle and straight movement; the more marked arc and circle movement being replaced by the unmarked straight movement) and also could be due to the pressure to make monosyllabic forms because the majority of BSL signs are monosyllabic. However, in

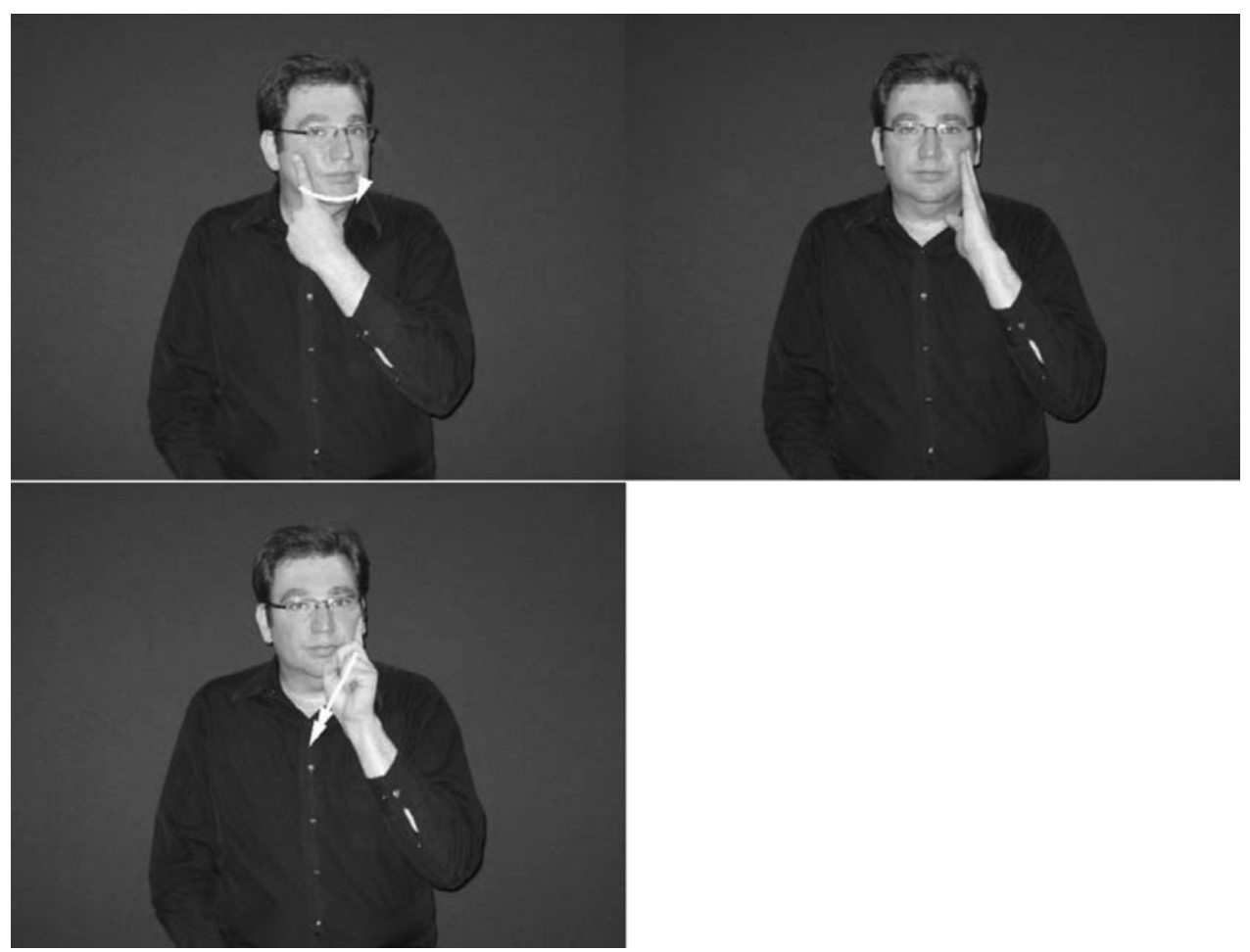

Figure 4. The nonsense sign in the two upper panels consists of two unmarked handshapes and two locations (on both sides of the face). This sign was reproduced, as shown in the lower panel, as the BSL sign for GIRL, with only one handshape (first handshape deleted) and only one location (first location deleted), and with substitution of a more marked movement (arc) with an unmarked (straight) movement, which is repeated (internal movement added). These are reproductions, by the same signer, of an actual stimulus and an actual response. 
the cases with nonpermissible combinations of movement (e.g., straight plus arc movements or straight plus circle movements), these omissions and deletions were legalizations.

Most internal movement errors were again omissions (all $p \mathrm{~s}<.001$ ). In contrast with handshape, however, substitutions occurred less often than omissions and additions (all $p \mathrm{~s}<.001)$ but almost as often as reductions $[t(52)=$ $-2.5, p=.018]$. The addition of an internal movement was sometimes combined with the deletion of a path movement (see, e.g., Figure 4). We included 14 nonsense signs that consisted of two internal movements, such as an aperture and finger wiggling, or repeated tapping of the signer's body. This error type is an example of legalization, since it has been proposed (for ASL) that combinations of two internal movements are not permissible in monomorphemic signs or compounds (Brentari, 2006; Perlmutter, 1992).

Most location errors were once again omissions $(n=$ 105). These were significantly more frequent than any other error type (all $p \mathrm{~s}<.001$ ). Of the 128 stimuli, 46 had two locations. All cases of location omission involved the deletion of one of two locations in the nonsense sign, in accordance with the Battison constraint (see Figure 4). This pattern is a clear case of legalization following the phonotactics of BSL.

Substitutions of location could involve the substitution of one location with an allophonic variant of the locations specified in the nonsense sign (this happened in 5 of the 23 cases of location substitutions). Interestingly, 7 of the location substitutions involve a second distinct location being substituted by neutral space (e.g., a nonsense sign moving from shoulder to chin was reproduced as moving from shoulder to neutral space). Location additions involved using the neutral space as a second location (9 instances) when the nonsense sign was articulated on the head. This is possibly because the neutral space is the most frequently used location for BSL signs and because there are signs in BSL that move from the body to the outer space. Using the BSL dictionary (British Deaf Association, 1992), we counted how many signs are articulated in different locations. This count gave us an estimate of 1,022 signs articulated in the neutral space, followed by 94 signs articulated on the nondominant hand and 91 on the chest (out of the 1,737 signs in the dictionary). We observed only one case of addition of another location within the same major phonological location (e.g., the nonsense sign was articulated on the stomach, and in the reproduction, the chest was added-i.e., a location within the major phonological location of the trunk).

In summary, omissions were the most frequent type of error for the path movement, internal movement, and location parameters but not for the handshape parameter, in which substitutions were instead the most common type. Omissions tended to involve the deletion of illegal or infrequent components of the nonsense signs (e.g., a second movement, location, or handshape). Similarly, substitutions involved the replacement of parameters with legal ones (legalizations) or with more frequent parameters (simplifications).

\section{Phonological Legality and Complexity}

The previous analysis might be taken as indicating that most errors involved the use of phonotactic knowledge to correct illegal signs. This was not the case, however. First, as was noted previously, there were more errors involving signs in second position (which were all phonotactically legal) than in first position (of which only half were illegal). Second, an analysis of the errors in first position alone revealed no difference between the numbers of changes made to legal signs ( 81 in total) versus illegal signs (95 in total) $\left(F_{1}<1\right)$. There was no effect of AoA in this analysis, and no interaction of AoA with sign legality. Third, one must keep in mind that the signs were coded for complexity (how many parameters they included). The complexity measure gives an indication of the role of phonological legality (with more complex nonsense signs tending more often to be illegal). In a regression analysis, the number of errors in each position was treated as the dependent variable, and phonological complexity was the independent variable. There was no effect of complexity $(F \mathrm{~s}<1)$. It thus appears that although participants - irrespective of AoA-often used phonotactic knowledge to correct illegal signs, this tendency cannot explain all the data. For example, other kinds of phonological knowledge (e.g., the preference for unmarked over marked handshapes) also influenced the pattern of misperceptions.

\section{Vocalic Versus Consonantal Parameters}

The overall analysis showed that movement (a "vocalic" parameter; Sandler, 1989) is more mutable than location (a "consonantal" parameter). According to Corina and Hildebrandt (2002), handshape is vocalic if it changes during a sign, but it is consonantal if it does not. In a final analysis, therefore, handshape errors were categorized as being either vocalic (the 48 handshape omissions, which all involved deletion of a second handshape and hence deletion of a handshape change) or consonantal (the other 152 handshape errors), and they combined, respectively, either with the path and internal movement errors (to form a single "vocalic" category) or with the location errors (to form a single "consonantal" category). There were more vocalic (mean per subject $=7.48$ ) than consonantal errors (mean per subject $=5.85)[F(1,48)=9.2, p<.005]$. Note, however, that the categorization of handshape omissions as "vocalic" is not unproblematic. Although these omissions involved the deletion of handshape movements, they of course also involved the deletion of the handshapes themselves (so, they may be "consonantal" errors too). This proviso notwithstanding, this analysis once again suggests that consonantal parameters are less mutable in sign recognition than are vocalic parameters.

\section{DISCUSSION}

This study examined the roles that different phonological parameters of BSL signs play during online sign processing, and how these roles are affected by AoA. Consistent with our predictions, the location parameter was the least affected major phonological parameter in the sign misperceptions of all AoA groups. Furthermore, path movement 
tended to be the most strongly affected parameter for the native and the childhood signers, but not for the adolescent signers. It appears that location is the least ambiguous parameter during online sign recognition and, as we will argue in a moment, this is the most plausible explanation for the low proportion of location misperceptions. The differences among the three parameters suggest that they indeed play different roles during sign recognition; the AoA effect suggests in addition that the role of the movement parameter depends on age of exposure to BSL.

\section{Effects of Phonological Parameter}

Our findings with regard to the high proportion of handshape misperceptions are consistent with related findings in sign production (Hohenberger et al., 2002; Klima \& Bellugi, 1979; Newkirk, Klima, Pedersen, \& Bellugi, 1980). Our results are also consistent with findings in sign language aphasia (Corina, 2000) and sign language acquisition (e.g., Conlin, Mirus, Mauk, \& Meier, 2000) that point to differences between location and handshape. However, unlike data on slips of the hand in German Sign Language (Hohenberger et al., 2002), the movement parameter was most heavily affected in the misperception errors (at least for the native and childhood signers). The present data thus add to a growing body of evidence showing variability among the effects of sign parameters of signs within and across different types of processing and different types of task.

In particular, the low proportion of misperceptions of the location parameter relative to the movement and handshape parameters indicates that these phonological parameters are used differently during the sign recognition process. Participants tend not to allow their perception of location to change. In priming tasks, inhibition between primes and targets sharing location (Carreiras et al., 2008; Corina \& Emmorey, 1993) has been interpreted as evidence that location guides the early stages of sign recognition. Inhibition between signs that share the same location can be explained as competition between sign candidates that is activated early during sign access on the basis of the shared location feature (Carreiras et al., 2008). Such inhibitory effects have not been observed for the handshape parameter. The inhibitory effects of phonological similarity are consistent with models of spoken-word recognition, which postulate a process of relative evaluation of possible lexical candidates (Luce \& Pisoni, 1998; McClelland \& Elman, 1986; Norris \& McQueen, 2008). Corina and Knapp (2006) noted that in spoken-word recognition, inhibitory effects have been reported for word onset information. Given that location is the first parameter to be identified in gating tasks (Emmorey \& Corina, 1990; Grosjean, 1981), Corina and Knapp suggested that the elements in words and signs that are recognized first may be more important for recognition than other elements. This would explain why the location parameter was the least affected in the sign misperceptions.

Inherent differences between the location parameter and the movement and handshape parameters in inventory size, saliency, and variability-like differences between vowels and consonants in speech-could also account for the differences in sign misperceptions. Regarding inventory size, 36 different locations are listed in the BSL dictionary (British Deaf Association, 1992), in contrast with 57 different handshapes. According to Hohenberger et al. (2002), the reason why handshape is so frequently involved in production errors may have to do with the combination of a large inventory size and the need for fine motor programs, which may lead to mis-selection during sign production. Although there are no more movements than locations (34 types of movement are listed in the BSL dictionary, including internal movements), movement may be more complicated than location, as exemplified by the lack of consensus in the description and classification of the movement parameter. Furthermore, the movement inventory is greatly increased when it is used in more expressive and iconic aspects of signed languages, such as in classifier constructions (variations in speed, size, and rhythm, which have morphemic status in BSL) and in poetry, rather than when it is used purely phonologically in lexical signs (Sandler \& Lillo-Martin, 2006).

Inventory size differences are thus consistent with the observed processing differences. The spoken-language version of this hypothesis, however, was examined by Cutler et al. (2000), who tested the vowel mutability effect in the word reconstruction task in two spoken languages with different vowel inventory size: Dutch and Castilian Spanish. Similar vowel mutability effects were observed in both languages, suggesting that vowel inventory size does not explain the vowel mutability effect. It is thus unlikely that inventory-size differences are the cause of the parameter effects in sign misperception.

Another possible account is based on perceptual saliency. For handshape, the small articulators (hand, fingers) reduce the parameter's perceptual saliency, perhaps making it more susceptible to perception errors. In contrast, movements are considered to be signs' most sonorous elements (e.g., Brentari, 1990; Coulter \& Anderson, 1992; Perlmutter, 1992), and hence they are thought to be more salient than handshapes and locations (though some have argued that it is the combination of movement and location that is the sign's most salient aspect; Corina \& Knapp, 2006; Dye \& Shih, 2006; Hildebrandt \& Corina, 2002). It is unlikely that saliency differences could explain the present results. In the speech modality it has been shown that although vowels are acoustically more salient than consonants (Crystal \& House, 1988a, 1988b; Fry, 1979), vowels take longer to identify than consonants (Cutler, van Ooijen, Norris, \& Sánchez-Casas, 1996; van Ooijen, 1994; van Ooijen, Cutler, \& Norris, 1991; van Ooijen et al., 1992). Despite the saliency of vowels, it thus appears that their identity is not easily recognizable and that they are more ambiguous than consonants (van Ooijen, 1996). The same could conceivably hold for the movement parameter in signs. Although movement is the most sonorous and dynamic component of the sign, its identity may take longer to be unambiguously identified as it unfolds over time (as indeed observed in gating; Emmorey \& Corina, 1990; Grosjean, 1981).

Ambiguity of vowel identity is connected to the fact that vowels are more variable in their acoustic realizations than consonants (Ladefoged, 1989; Peterson \& Barney, 1952; Strange, Jenkins, \& Johnson, 1983). In the word re- 
construction task (van Ooijen, 1996) the higher proportion of vowel changes than consonant changes could reflect listeners' uncertainty about precise vowel identity. In sign languages, it is plausible that there may also be more variability in movement (and to a lesser extent in handshape) than in location, because movements (and handshapes) can be produced at different speeds, sizes, and rhythms depending on the message and the communicative situation (e.g., public signing, emphasis). According to this view, the variability of the phonological parameter would be connected to its mutability. That is, if signers change anything in a sign, they should change the parts that are normally more variable. Emmorey et al. (2003), however, discussed the lack of categorical perception for location in terms of the more variable and continuous nature of its articulation, as compared with handshape (which was perceived categorically; but see Mathur \& Best, 2007, for contradictory evidence). As noted by Emmorey et al., whispering in ASL, for example, can displace signs to different locations, whereas the articulation of the handshape is less dramatically altered during whispering.

As with the account based on inventory size, there are some grounds for questioning whether the differences between phonological parameters of signs in misperceptions are based on greater variability in the movement and handshape parameters than in the location parameter. As was argued previously, it is unlikely that saliency is the source of the parameter effect (the most salient parameter, movement, is the most likely to be misperceived). The most plausible account of these results is, therefore, that the location parameter is the least ambiguous parameter and can thus be identified the fastest. Data from nonsigners support this conclusion. In Mann, Marshall, Mason, and Morgan (2008), hearing nonsigning children were asked to repeat single nonsense signs (legal signs with no meaning), and their productions were scored for accuracy. Nonsigners were able to repeat location information without difficulty, but were less accurate in repeating handshapes and movements. Location thus appears to be the easiest parameter to perceive accurately.

\section{Effects of Error Type \\ and Phonotactic Knowledge}

We also found differences between phonological parameters in the types of errors. For the handshape parameter only, substitutions occurred most frequently. This occurrence is potentially related to the large inventory size and the reduced saliency of the handshape parameter, especially for complicated marked handshapes, which are harder to perceive and to produce than are unmarked handshapes. The substitution of a marked handshape with an unmarked one is an example of simplification, which has been documented in developmental studies of speech (Smith, 1973, 2004) and sign (e.g., Morgan, 2006). Omissions of handshapes involved the second handshape in the nonsense sign, but sometimes the second handshape was substituted with an unmarked handshape instead of being omitted. The behavior of the deaf signers in the present task is consistent with the phonotactic structure of BSL, which shows a preference to unmarked handshapes even when there are two handshapes in a sign.

For the movement (path and internal movement) and location parameters, the most frequently occurring type of error was omission. The behavior of the participants was again consistent with the phonotactics of BSL, according to which some combinations of path movements (e.g., arc plus straight) are not permissible. The path substitutions can be characterized as simplifications, in which a marked arc or circle movement was substituted by an unmarked straight movement, or as legalizations, resulting in a permissible combination of path movements. In a similar vein, omissions of the second location in the nonsense sign resulted in an acceptable phonotactic structure, consistent with the Battison constraint.

Although participants often used phonotactic knowledge to correct illegal signs, this tendency cannot explain all of the data, since-contrary to what a purely phonotactics-based account would predict - we did not find more errors for the nonsense signs that violated phonotactic constraints of BSL than for nonsense signs that did not. However, it seems that the proposed phonotactic constraints in the ASL literature have some psychological validity in BSL, and that BSL signers tend to follow these constraints even when faced with a task that does not require them to reconstruct signs.

\section{Effects of AoA}

The present data are consistent with a growing body of evidence showing a qualitatively different treatment of phonological parameters in native and nonnative signers. Overall, nonnative signers produced more misperception errors than did native signers, but this difference was not significant. However, native and nonnative signers did differ in the parameters they changed in the nonsense signs. Although native and childhood signers changed mostly the movement parameter, adolescent signers changed the handshape parameter most often. This difference suggests that there is a qualitative difference in the processing of form-based properties of signs between the late-acquiring signers and the signers who learned BSL earlier in life. Hildebrandt and Corina (2002) reported that most signers judged movement properties as most salient, whereas nonnative signers' responses indicated handshape as the most salient factor. Thus, although native and childhood signers treat movement as "vocalic," adolescent signers could treat handshape as more salient and hence as more "vocalic." Dye and Shih (2006) suggested that it is the combination of movement and location parameters that serve as initial input for lexical access in native signers, but that movement may be more critical for nonnative signers (see also Corina \& Knapp, 2006). For this reason, movement may be more resistant to change in their misperceptions.

Related observations come from earlier studies on ASL looking at the effects of linguistic experience on the processing of the sign parameters. No differences were found between signers (native and nonnative) and nonsigning hearing controls in the types of visual confusions among 
handshapes (Lane, Boyes-Braem, \& Bellugi, 1976). Similar results for the location parameter were reported by Poizner and Lane (1978) in a study in which deaf and nonsigning hearing participants were asked to identify locations under conditions of visual noise. These results suggest that linguistic experience does not affect the saliency of the visual features critical to the identification of handshape and location. The categorization of movement, however, seems to be affected by exposure to sign language (Emmorey et al., 2003). Poizner $(1981,1983)$ found differences between signers and nonsigners in a similarity judgment task for point-light motion displays, and Wilson (2001) showed that experience with ASL affects the perception of apparent motion - that is, the perception of a single moving object when a static object appears at one location, followed rapidly by a static object at another location. These findings are thus consistent with the present results. It appears that the processing of the movement parameter is influenced by knowledge and the use of sign language, but the processing of handshape and location is not. Thus, the AoA effect observed in the present article probably reflects a change in the way movement is processed rather than a change in the way handshape is processed.

\section{Implications for Models of Sign Phonology}

Phonological models (Brentari, 1990, 1998; Sandler, 1989) agree that location, movement, and handshape are all part of the representation of signs, but they differ in how the three parameters are related to each other at a higher ("segmental" or "syllabic") level of organization. According to Sandler, movement and location should be grouped together and handshape set apart; according to Brentari (1990, 1998), location and handshape should be grouped together, and movement set apart. The data offer some support for the Brentari $(1990,1998)$ model: For the native and childhood signers, movement errors were the most common. However, the data from the adolescents offer some support for the Sandler model: For these participants, handshape errors were the most common. Furthermore, both models group location with one other parameter, so neither model can explain why, irrespective of AoA, location was least often misperceived. It is important that one note, however, that the present study was not designed to distinguish between these phonological models.

\section{Differing Roles of Parameters in Sign Recognition}

Our main question was whether linguistic differences between the phonological parameters of signs influence sign recognition. In the speech domain, the vowel mutability effect in word spotting and word reconstruction (van Ooijen, 1996) has been interpreted as evidence that consonants provide more reliable information about lexical identification than do vowels, and hence constrain lexical selection more tightly (i.e., allow fewer potential candidates) than vowels. We believe that this is the case with the location parameter in comparison with the other phonological parameters of signs (with perhaps the exception of handshapes that do not involve any sign-internal handshape changes, which may also be "consonantal"). In priming tasks, inhibition between signs that share the same location can be explained as competition between sign candidates activated early during sign access on the basis of the shared location feature (Carreiras et al., 2008; Corina \& Emmorey, 1993; see also Dye \& Shih, 2006, for facilitatory effects). Evidence from TOF states (Thompson, Emmorey, \& Gollan, 2005) and gating studies (e.g., Grosjean, 1981) in ASL demonstrates that some information regarding handshape and location is available sooner than details of movement. During sign recognition, the identification of location thus occurs first and produces the initial cohort of candidate signs. Conceivably, in a misperception error, an initial cohort is produced mainly by the identification of location. An illegal movement follows later on, perhaps, but the existence of an already plausible set of lexical candidates may affect perception of movement.

It seems that native signers, like native speakers, are more inclined to preserve "consonantal" parameters because they are unambiguous during early stages of sign recognition and are therefore more reliable in guiding sign recognition than are the "vocalic" parameters. Late learners of sign language are also inclined to preserve the location parameter but, unlike native and childhood signers, they treat movement as less mutable than handshape. Their doing so may be related to the fact that the movement is the most salient component of the sign; for late signers, this perceptual saliency may guide lexical access. It thus appears that lexical access is qualitatively different between late and early learners of sign language: It may be more perceptually bound for late than for early learners (Mayberry, 1994).

Interestingly, some linguistic treatments of path movement have questioned its informational value. Sandler and Lillo-Martin (2006) have argued that path movements add little information that is not predictable to the sign, so that deleting them merely decreases the retrievability of many signs. This redundancy has even led some researchers to claim that movement is not a phonological primitive (e.g., Channon, 2002; van der Hulst, 1993). If movement information is not always central to uniquely identifying a sign, then signers could learn that when sign access fails, it is better to adjust movement information than location or handshape information. This hypothesis requires information on the statistical distribution of location, handshape, and movement in the BSL lexicon. In speech, the distribution of vowels and consonants means that changing a consonant in a word is about twice as likely to produce another word as changing a vowel. Hence, when lexical access fails, listeners would rather modify the vowel than the consonant because vowel changes are more likely to yield the correct word, whereas consonant changes are more likely to result in a lexical neighbor (Cutler et al., 2000). Preliminary observations on minimal pairs in BSL (i.e., signs that differ by only one phonological parameter) suggest that there are more minimal pairs based on location than on movement and handshape (R. Thompson, personal communication).

To conclude, our data on misperception errors in sign spotting are similar to those on misperception errors in word spotting (van Ooijen, 1996). We found that native 
deaf signers, just like native speakers, tend to change the vocalic components of nonsense input. To the extent that homologies involving vowels and consonants across signed and spoken languages are valid, this tendency suggests that there are basic, modality-independent distinctions in the signal properties of language and the way they are used during language comprehension. When faced with the task of spotting lexical items embedded in nonsense contexts, native signers and native speakers tend to preserve mostly location parameters or consonants, as appropriate. These phonological components appear to be more reliable in guiding lexical access than the movement parameters and the vowels.

\section{AUTHOR NOTE}

This research was funded by ESRC Grant 000-23-1450 to G.M. and J.M.M. We thank all our deaf participants, as well as three anonymous reviewers for constructive comments. We also thank Tanya Denmark, Frances Elton, Jordan Fenlon, and Tyron Woolfe for their help in preparing the stimuli. We are indebted to the Deafness Cognition and Language Research Centre at UCL, where the majority of this research was carried out. Address correspondence to E. Orfanidou, City University London, Department of Language Communication Science, Northampton Square, London EC1V 0ET, England (e-mail: eleni.orfanidou.1@city.ac.uk).

\section{REFERENCES}

Battison, R. (1978). Lexical borrowing in American Sign Language. Silver Spring, MD: Linstok Press.

Bellugi, U., Klima, E. S., \& SiPle, P. (1975). Remembering in signs. Cognition, 3, 93-125.

Bonatti, L. L., PeÑa, M., Nespor, M., \& Mehler, J. (2005). Linguistic constraints on statistical computations. Psychological Science, 16, 451-459.

Bonatti, L. L., Peña, M., Nespor, M., \& Mehler, J. (2007). On consonants, vowels, chickens, and eggs. Psychological Science, 18, 924925.

Brentari, D. (1990). Theoretical foundations of American Sign Language phonology. Unpublished doctoral dissertation, University of Chicago.

Brentari, D. (1998). A prosodic model of sign language phonology. Cambridge, MA: MIT Press.

BRENTARI, D. (2006). Effects of language modality on word segmentation: An experimental study of phonological factors in a sign language. In L. Goldstein, D. Whalen, \& C. Best (Eds.), Papers in laboratory phonology VIII (pp. 155-164). The Hague: Mouton de Gruyter.

British Deaf Association (1992). Dictionary of British Sign Language. London: Faber and Faber.

Caramazza, A., Chialant, D., Capasso, R., \& Miceli, G. (2000). Separable processing of consonants and vowels. Nature, 403, 428-430.

Carreiras, M., Gutiérrez-Sigut, E., Baquero, S., \& Corina, D. (2008). Lexical processing in Spanish Sign Language. Journal of Memory \& Language, 58, 100-122.

Channon, R. (2002). Beads on a string? Representations of repetition in spoken and signed languages. In R. Meier, K. Cormier, \& D. QuintoPozos (Eds.), Modality and structure in signed and spoken language (pp. 65-87). Cambridge: Cambridge University Press.

Conlin, K., Mirus, G. R., Mauk, C., \& Meier, R. P. (2000). The acquisition of first signs: Place, handshape, and movement. In C. Chamberlain, J. P. Morford, \& R. I. Mayberry (Eds.), Language acquisition by eye (pp. 51-69). Mahwah, NJ: Erlbaum.

Corina, D. (1990). Reassessing the role of sonority in syllable structure: Evidence from a visual-gestural language. In M. Ziolkowski, M. Noske, \& K. Deaton (Eds.), Proceedings from the 26th Annual Meeting of the Chicago Linguistics Society (Vol. 2, pp. 33-44). Chicago: The Chicago Linguistics Society.

Corina, D. (2000). Some observations regarding paraphasia in American Sign Language. In K. Emmorey \& H. Lane (Eds.), The signs of language revisited: An anthology to honor Ursula Bellugi and Edward Klima (pp. 493-507). Mahwah, NJ: Erlbaum.

Corina, D., \& Emmorey, K. (1993, November). Lexical priming in American Sign Language. Poster presented at the 34th Annual Meeting of the Psychonomic Society, Washington DC.

Corina, D., \& Hildebrandt, U. (2002). Psycholinguistic investigations of phonological structure in American Sign Language. In R. P. Meier, K. Cormier, \& D. Quinto-Pozos (Eds.), Modality and structure in signed and spoken languages (pp. 88-111). Cambridge: Cambridge University Press.

Corina, D., \& Knapp, H. P. (2006). Lexical retrieval in American Sign Language production. In L. M. Goldstein, D. H. Whalen, \& C. T. Best (Eds.), Papers in laboratory phonology 8: Varieties of phonological competence (pp. 213-240). Berlin: Mouton de Gruyter.

Coulter, G. R., \& ANDERSON, S. R. (1992). Introduction. In G. Coulter (Ed.), Current issues in ASL phonology: Phonetics and phonology (Vol. 3, pp. 1-17). San Diego: Academic Press.

Crasborn, O. (2001). Phonetic implementation of phonological categories in Sign Language of the Netherlands. Unpublished doctoral dissertation, Netherlands Graduate School of Linguistics, Utrecht, The Netherlands.

Crasborn, O., \& van der Koolj, E. (1997). Relative orientation in sign language phonology. In J. Coerts \& H. de Hoop (Eds.), Linguistics in the Netherlands 1997 (pp. 37-48). Amsterdam: John Benjamins.

Crystal, T. H., \& House, A. S. (1988a). Segmental durations in connected-speech signals: Current results. Journal of the Acoustical Society of America, 83, 1553-1573.

Crystal, T. H., \& House, A. S. (1988b). Segmental durations in connected-speech signals: Syllabic stress. Journal of the Acoustical Society of America, 83, 1574-1585.

CUtler, A., \& Norris, D. (1988). The role of strong syllables in segmentation for lexical access. Journal of Experimental Psychology: Human Perception \& Performance, 14, 113-121.

Cutler, A., Sebastián-Gallés, N., Soler-Vilageliu, O., \& van OolJen, B. (2000). Constraints of vowels and consonants on lexical selection: Cross-linguistic comparisons. Memory \& Cognition, 28, 746-755.

Cutler, A., van Ooijen, B., Norris, D., \& Sánchez-Casas, R. (1996). Speeded detection of vowels: A cross-linguistic study. Perception \& Psychophysics, 58, 807-822.

Dumay, N., Frauenfelder, U. H., \& Content, A. (2002). The role of the syllable in lexical segmentation in French: Word-spotting data. Brain \& Language, 81, 144-161.

Dye, M. W. G., \& SHIH, S. (2006). Phonological priming in British Sign Language. In L. M. Goldstein, D. H. Whalen, \& C. T. Best (Eds.), Papers in laboratory phonology 8 (pp. 241-263). Berlin: Mouton de Gruyter.

Emmorey, K., \& Corina, D. (1990). Lexical recognition in sign language: Effects of phonetic structure and morphology. Perceptual \& Motor Skills, 71, 1227-1252.

Emmorey, K., McCullough, S., \& Brentari, D. (2003). Categorical perception in American Sign Language. Language \& Cognitive Processes, 18, 21-45.

Forster, K. L., \& Forster, J. C. (2003). DMDX: A Windows display program with millisecond accuracy. Behavior Research Methods, Instruments, \& Computers, 35, 116-124.

FrY, D. B. (1979). The physics of speech. Cambridge: Cambridge University Press.

Grosjean, F. (1981). Sign and word recognition: A first comparison. Sign Language Studies, 32, 195-220.

Hallé, P. A., Segui, J., Frauenfelder, U., \& Meunier, C. (1998). Processing of illegal consonant clusters: A case of perceptual assimilation, Journal of Experimental Psychology: Human Perception \& Performance, 24, 592-608.

Hildebrandt, U., \& CoRINA, D. (2002). Phonological similarity in American Sign Language. Language \& Cognitive Processes, 17, 593-612.

Hohenberger, A., Happ, D., \& Leuninger, H. (2002). Modalitydependent aspects of sign language production: Evidence from slips of the hands and their repairs in German Sign Language. In R. P. Meier, K. Cormier, \& D. Quinto-Pozos (Eds.), Modality and structure in signed and spoken languages (pp. 112-142). Cambridge: Cambridge University Press. 
JAKoBson, R. (1968). Child language, aphasia, and phonological universals. The Hague: Mouton. (Original work published 1941)

KarnopP, L. B. (2002). Phonology acquisition in Brazilian Sign Language. In G. Morgan \& B. Woll (Eds.), Directions in sign language acquisition (pp. 29-53). Amsterdam: John Benjamins.

Klima, E. S., \& Bellugi, U. (1979). The signs of language. Cambridge, MA: Harvard University Press.

LADEFOGED, P. (1989). A note on "information conveyed by vowels." Journal of the Acoustical Society of America, 85, 223-224.

Lane, H., Boyes-Braem, P., \& Bellugi, U. (1976). Preliminaries to a distinctive feature analysis of American Sign Language. Cognitive Psychology, 8, 263-289.

LidDELL, S., \& JoHnson, R. (1989). American Sign Language: The phonological base. Sign Language Studies, 64, 197-277.

LuCE, P. A., \& PISONI, D. B. (1998). Recognizing spoken words: The neighborhood activation model. Ear \& Hearing, 19, 1-36.

Mann, W., Marshall, C., Mason, K., \& Morgan, G. (2008). The interplay between phonology and phonetics in sign language development: Data from nonsense sign repetition. Manuscript submitted for publication.

Mathur, G., \& Best, C. (2007, March). Three experimental techniques for investigating sign language processing. Paper presented at the 20th annual CUNY Conference on Human Sentence Processing, La Jolla CA

MAYBERRY, R. I. (1994). The importance of childhood to language acquisition: Evidence from American Sign Language. In J. C. Goodman \& H. C. Nusbaum (Eds.), The development of speech perception (pp. 57-90). Cambridge, MA: MIT Press.

MAYberRY, R. I., \& Fischer, S. D. (1989). Looking through phonological shape to lexical meaning: The bottleneck of non-native sign language processing. Memory \& Cognition, 17, 740-754

MAYBERRY, R. I., LOCK, E., \& KAZMI, H. (2002). Linguistic ability and early language exposure. Nature, $\mathbf{4 1 7}, 38$.

McClelland, J. L., \& Elman, J. L. (1986). The TRACE model of speech perception. Cognitive Psychology, 18, 1-86.

McQueEN, J. M. (1998). Segmentation of continuous speech using phonotactics. Journal of Memory \& Language, 39, 21-46.

MeIER, R. P. (2000). Shared motoric factors in the acquisition of sign and speech. In K. Emmorey \& H. Lane (Eds.), The signs of language revisited: An anthology to honor Ursula Bellugi and Edward Klima (pp. 333-356). Mahwah, NJ: Erlbaum.

Moates, D. R., Bond, Z. S., \& Stockmal, V. (2002). Phoneme frequency in spoken word reconstruction. In C. Gussenhoven \& N. Warner (Eds.), Laboratory phonology 7 (pp. 141-170). Berlin: Mouton de Gruyter.

Moates, D. R., \& Russell, S. (1999). Word reconstruction with printed materials. Paper presented at the conference on Basic Mechanisms of Language and Language Disorders, Leipzig.

Morgan, G. (2006). Children are just lingual: The development of phonology in British Sign Language (BSL). Lingua, 116, 1507-1523.

Newkirk, D., Klima, E., Pedersen, C., \& Bellugi, U. (1980). Linguistic evidence from slips of the hand. In V. A. Fromkin (Ed.), $E r$ rors in linguistic performance: Slips of the tongue, ear, pen, and hand (pp. 165-197). New York: Academic Press.

NewPORT, E. L. (1990). Maturational constraints on language learning. Cognitive Science, 14, 11-28.

Norris, D., \& McQueen, J. M. (2008). Shortlist B: A Bayesian model of continuous speech recognition. Psychological Review, 115, 357-395.

Orfanidou, E., Adam, R., Morgan, G., \& McQueen, J. M. (2008). Segmentation in signed and spoken language: Different modalities, same segmentation procedure. Manuscript submitted for publication.

Perlmutter, D. (1992). Sonority and syllable structure in American Sign Language. Linguistic Inquiry, 23, 407-422.

Peterson, G. E., \& Barney, H. L. (1952). Control methods used in a study of the vowels. Journal of the Acoustical Society of America, 24 $175-184$

Poizner, H. (1981). Visual and "phonetic" coding of movement: Evidence from American Sign Language. Science, 212, 691-693.

Poizner, H. (1983). Perception of movement in American Sign Lan- guage: Effects of linguistic structure and linguistic experience. Perception \& Psychophysics, 33, 215-231.

Poizner, H., \& LANE, H. (1978). Discrimination of location in American Sign Language. In P. Siple (Ed.), Understanding language through sign language research (pp. 271-287). New York: Academic Press.

Raven, J. C. (1938). Progressive matrices: A perceptual test of intelligence, individual form. London: $\mathrm{H}$. K. Lewis.

REPP, B. (1984). Closure duration and release burst amplitude cues to stop consonant manner and place of articulation. Language \& Speech, 27, 245-254.

SANDLER, W. (1989). Phonological representation of the sign: Linearity and nonlinearity in American Sign Language. Dordrecht: Foris.

SANDLER, W., \& Lillo-Martin, D. (2006). Sign language and linguistic universals. Cambridge: Cambridge University Press.

Siedlecki, T., \& Bonvillian, J. D. (1993). Location, handshape and movement: Young children's acquisition of the formational aspects of American Sign Language. Sign Language Studies, 78, 31-52.

Sмiтн, N. V. (1973). The acquisition of phonology: A case study. Cambridge: Cambridge University Press.

Sмiтh, N. V. (2004). Universal tendencies in the child's acquisition of phonology. In B. Lust \& C. Foley (Ed.), First language aquisition: The essential readings (pp. 294-306). Oxford: Blackwell.

Stokoe, W. C., JR., Casterline, D. C., \& Croneberg, C. G. (1965). A dictionary of American Sign Language on linguistic principles. Washington, DC: Gallaudet College Press.

Strange, W., Jenkins, J. J., \& Johnson, T. L. (1983). Dynamic specification of coarticulated vowels. Journal of the Acoustical Society of America, 74, 695-705.

Sutton-Spence, R., \& Woll, B. (1999). The linguistics of BSL: An introduction. Cambridge: Cambridge University Press.

Thompson, R., Emmorey, K., \& Gollan, C. G. (2005). Tip of the fingers: Experiences by deaf signers. Psychological Science, 16, 856-860.

UYeCHI, L. (1996). The geometry of visual phonology. Stanford, CA: CSLI Publications.

VAN DER Hulst, H. (1993). Units in the analysis of signs. Phonology, 10, 209-242.

VAN OOIJEN, B. (1994). The processing of vowels and consonants. Unpublished doctoral dissertation, University of Leiden, Leiden, The Netherlands.

van OolJen, B. (1996). Vowel mutability and lexical selection in English: Evidence from a word reconstruction task. Memory \& Cognition, 24, 573-583.

van Ooijen, B., Cutler, A., \& Norris, D. (1991). Detection times for vowels versus consonants. In Eurospeech 91: Proceedings of the 2nd European Conference on Speech Communication and Technology (Vol. 3, pp. 1451-1454). Genova, Italy: European Speech Communication Association.

van Ooljen, B., Cutler, A., \& Norris, D. (1992). Detection of vowels and consonants with minimal acoustic variation. Speech Communication, 11, 101-108.

WILSON, M. (2001). The case for sensorimotor coding in working memory. Psychonomic Bulletin \& Review, 8, 44-57.

Wilson, M., \& EMmorey, K. (1997). A visuospatial "phonological loop" in working memory: Evidence from American Sign Language. Memory \& Cognition, 25, 313-320.

\section{NOTE}

1. For this reason, we did not perform analyses by items. The same item could be involved in different conditions (e.g., an item in which both location and handshape errors occurred), so it was not clear whether items could be considered to be independent repeated measures. This issue did not arise in the analyses by participants, in which the errors were counted per participant, irrespective of whether they occurred in the same or in different items.

(Manuscript received June 16, 2008; revision accepted for publication November 8,2008 .) 